\title{
A liderança carismática em organizações de saúde do sul de Santa Catarina
}

\author{
Maria Flávia Baesso \\ Gisele Silveira Coelho Lopes \\ Diogo Pereira Morais
}

Andrigo Rodrigues
Especialista em Gestão de Pessoas com foco em Coaching, Universidade do Extremo Sul Catarinense (UNESC), Brasil - flaviabaesso@hsjb.com.br Doutoranda em Administração, Universidade do Extremo Sul Catarinense (UNESC), Brasil - giselelopes@unesc.net

Mestrando em Administração pela Universidade do Vale do Itajai (UNIVALI), Universidade do Vale do Itajaí (UNIVALI), Brasil diogomorais03@hotmail.com

Mestre em Ciência e Engenharia de Materiais, Universidade do Extremo Sul Catarinense (UNESC), Brasil - andrigo@unesc.net

\section{RESUMO}

Este trabalho objetiva identificar o nível de liderança carismática em profissionais que ocupam cargos de gestão em organizações de saúde do sul de Santa Catarina. Foi utilizado como base teórica Conger et al (1997) que desenvolveu um modelo teórico de liderança carismática composto por cinco dimensões, i) visão estratégica e articulação (SVA); ii) sensibilidade ao ambiente (SE); iii) sensibilidade aos membros (SMN); iv) risco pessoal (PR); v) comportamento não convencional (VB). Esta pesquisa se caracterizou como descritiva e de campo, cuja análise dos dados foi predominantemente quantitativa. Este estudo foi realizado em duas organizações de saúde (hospital (1) e clínica de saúde (2)) localizadas na região sul de Santa Catarina (Brasil). No hospital há 262 trabalhadores, porém somente 220 aceitaram participar da pesquisa, o que corresponde a $84 \%$ dos respondentes. Na clínica de saúde há 43 trabalhadores, porém somente 38 aceitaram participar da pesquisa, o que corresponde a $88 \%$ dos respondentes. Os resultados indicaram a inexistência de diferença significativa nos escores de liderança carismática. Neste sentido, foi possível constatar que os líderes apresentaram, em geral, médias superiores a 5 pontos, em uma escala de 6 (mínimo 1 e máximo 7). Esse resultado indica que em ambas instituições os líderes apresentaram tendência para a liderança carismática.

Palavras-chave: Liderança. Carisma. Hospital. Saúde.

\section{The charismatic leadership in health organizations in the south of Santa Catarina}

\begin{abstract}
This study aims to identify the level of charismatic leadership in management positions inside health organizations from the South of Santa Catarina. The theoretical support was based on Conger, et al (1997), which developed a model of leadership composed by five dimensions, i) strategic vision and articulation (SVA); ii) sensitivity to the enviroment (SE); iii) sensitivity to the members (SMN); iv) personal risk (PR); v) unconvencional behavior (VB). The study was characterized as a field research, descriptive and the data analysis was mostly quantitative. The research was made in two health organizations (hospital (1) and clinic (2)) based in the South of Santa Catarina (Brazil). The hospital has 262 employees but only 220 of them agreed to respond, which corresponds to $84 \%$ participants. The clinic has 43 employees and 38 of them responded the research, which corresponds to $88 \%$ participants. The results indicated that there is no significant difference in charismatic leadership scores. Therefore, it was possible to verify that the leaders generally present averages superior to 5 points, in a scale of 6 (minimum 1 and maximum 7). This result indicates that in both organizations the leaders presented tendency to charismatic leadership.
\end{abstract}

Keywords: Leadership. Charisma. Hospital. Health. 


\section{INTRODUÇÃO}

A liderança é um tema amplamente discutido em várias áreas do conhecimento. Pesquisadores se debruçaram em estudos que demonstram a compreensão acerca de uma definição do tema, sendo que é possível afirmar que a liderança ganha cada vez mais espaços em estudos relacionados ao contexto organizacional (OLIVEIRA; DELFINO, 2013).

Ao longo do tempo, a liderança foi investigada considerando diferentes perfis a partir do contexto social que as pessoas estavam inseridas. Max Weber (1925/1968) foi o primeiro pesquisador a contextualizar a liderança carismática como um dos três tipos de autoridade em uma sociedade: tradicional, racional-legal e carismática. Para Weber a liderança carismática era visível nos líderes religiosos e políticos que detinham do poder para curar, aconselhar e profetizar sobre as pessoas que o seguiam (CONGER, et al 1997). Entre as décadas de 1970 e 1980 estudos (DOW, 1969; WILLNER, 1984) ampliaram a liderança carismática para outros segmentos sociais e organizacionais. Esta corrente teórica defende que o líder carismático detém de personalidade distinta que atrai um contingente significativo de seguidores pelos ideais que defendem (CONGER, 2011).

Fixados esses pressupostos, vale destacar que a personalidade distinta da liderança carismática é conhecida como aquele que possui um "dom". Este dom está relacionado não somente às características intrínsecas do líder, mas como estas são percebidas pelos liderados que acreditam nos ideais e o seguem voluntariamente (GOMES; CRUZ, 2007). Na liderança carismática, o seguidor a partir dos valores partilhados pelo líder, manifesta motivação intrínseca para o cumprimento dos objetivos, além de expressar autoestima, sensação de autorrealização e identificação com os propósitos (FIOL; HARRIS; HOUSE, 1999). Líderes carismáticos defendem a motivação intrínseca como uma estratégia para influenciar os liderados a perceberem suas potencialidades, talentos e sentimentos de valorização pelo que fazem. Na medida em que o liderado percebe o valor do seu ofício, o líder carismático estimula-o para atitudes mais positivas em prol do sistema social que está inserido, ao prover um sentimento de identidade coletiva. Esse estilo de liderança remete aos liderados a busca para o alcance de propósitos que mobilize atitudes de otimismo em busca de resultados mais sistêmicos (GOMES; CRUZ, 2007).

É nessa linha de raciocínio que Conger et al (1997) perceberam que o processo de liderança carismática organizacional demanda responsabilidades inerentes a função do líder que envolve a identificação de oportunidades no ambiente externo e interno, para o desenvolvimento de uma direção organizacional adequada a realidade do momento. Essa responsabilidade outorgada ao líder remete a definição de objetivos e metas que vise o funcionamento da organização. Ciente da capacidade funcional da liderança, os autores desenvolveram um instrumento para medir o nível de carisma dos líderes organizacionais, composto por 5 (cinco) dimensões: i) visão estratégica e articulação (SVA); ii) sensibilidade ao ambiente (SE); iii) sensibilidade aos membros ( $\mathrm{SMN}$ ); iv) risco pessoal (PR); v) comportamento não convencional (VB). Os autores destacam a necessidade de novas investigações que atentem para testar o instrumento a partir de estudos empíricos em diferentes organizações. É nesta esteira, que este trabalho se dedica em testar o instrumento proposto, cujo objetivo é identificar o nível de liderança carismática em profissionais que ocupam cargos de gestão em organizações de saúde do sul de Santa Catarina.

\section{REFERENCIAL TEÓRICO}

A seguir serão discutidos teoricamente a liderança carismática nas organizações, com base no modelo teórico de Conger et.al (1997) que se propôs em avaliar o carisma do líder em 5 (cinco) dimensões de análise: i) visão estratégica e articulação (SVA); ii) sensibilidade ao ambiente (SE); iii) sensibilidade aos membros (SMN); iv) risco pessoal (PR); v) comportamento não convencional (VB). Estas dimensões são discutidas a seguir.

\subsection{A liderança carismática nas organizações}

A terminologia carisma na mitologia grega é caracterizada como sendo um dom dos deuses cujas proezas não possuíam explicação lógica. Já nas organizações religiosas o carisma era reconhecido como um talento advindo de um dom divino. Tinha como pressuposto essencial a forma como o profeta recebia o poder de Deus, desta forma os seguidores passavam a segui-lo, sendo considerado uma figura infalível. A partir dessa perspectiva o carisma começou a ser visualizado em diferentes contextos organizacionais (GOMES; CRUZ, 2007). Max Weber (1925/1968), pioneiro em discutir teoricamente a liderança carismática, retratou o perfil do líder como uma pessoa visionária e inspiradora com capacidade de resolver e mediar situações conflituosas, demonstrando aos liderados a segurança de sua capacidade de amenizar o sofrimento alheio. 
Nesta linha de raciocínio, Conger (2011) evidencia que a liderança carismática envolve os liderados a se motivarem para resolver situações complexas de forma visionária e inspiradora, ao passo que os seguidores observam no líder a figura de alguém que está disposto a resolver qualquer situação conflitante, que consiga manter o foco e direcionar os liderados.

Um estudo em organizações sociais buscou entender as evidências da liderança carismática. Os pesquisadores concluíram que os líderes que possuíam longa trajetória na organização, apresentaram maior tendência para liderança carismática. $O$ estudo ainda demonstra que a liderança carismática manifesta habilidades de criar novos procedimentos que proporcionam a viabilização do trabalho. Isto ocorre porque o líder possui o forte aspecto de dominação perante a equipe (SILVA; CARVALHO NETO, 2012). Um estudo experimental realizado com 247 estudantes de uma universidade, concluiu que os líderes carismáticos apresentaram comportamentos voltados para a solução de problemas cujas soluções não demandaram altas qualidades, mas com alta originalidade, pois apresentaram domínio social elevado. Outro ponto destacado pela pesquisa é que os líderes carismáticos tiveram comportamentos visionários para ambientes não estruturados, pois priorizaram valores direcionados a um futuro melhor. Dado seu caráter voltado para o alto envolvimento social, os autores concluíram que os líderes carismáticos não possuem perfil para a solução de problemas complexos que requerem altos níveis de qualidade e rigidez (BEDELL-AVERS; HUNTER; MUMFORD, 2008).

Considerando a forte característica de familiaridade com o contexto social, a liderança carismática apresenta emoções positivas em relação a outros estilos de liderança. Um estudo realizado com 93 líderes históricos que representaram diferentes papéis sociais, políticos e militares ao longo dos anos 20 até o início do século 21 , concluiu que os líderes carismáticos apresentam atitudes otimistas, mesmo quando enfrentam situações difíceis. Outra evidência apontada no estudo é que os líderes carismáticos utilizam da arte da oratória, com a habilidade de boa entonação vocal, eloquência e outras expressões não verbais, para transmitir mensagens rápidas para muitos liderados ao mesmo tempo. Isso significa que os líderes carismáticos utilizam de estratégias para influenciar seus liderados a respeito de visões positivas sobre o futuro (GRIFFITH et al, 2015).

\subsubsection{A liderança carismática: a visão estratégica e articulação}

Os líderes carismáticos apresentam maior propensão a disseminar uma visão inspiradora em suas organizações, pois disseminam a sua missão de vida e conquistam a atenção e admiração dos liderados. São líderes que cativam e, estrategicamente fazem uso de seus atributos comportamentais para agregar um maior número de seguidores. A liderança carismática reflete em uma visão de futuro compartilhada, idealizada e com articulação eficaz. Neste sentido, a visão estratégica é um componente evidente no comportamento do líder carismático, pois consegue perceber o ambiente interno e externo com mais facilidade. Essa característica é essencial para as organizações que objetivam sustentar uma vantagem competitiva no mercado (CONGER et al, 1997).

Nessa linha de raciocínio, é importante destacar que as organizações contemporâneas apresentam estruturas organizacionais mais enxutas e otimizadas. O modo de controle vertical gerente-subordinados não funciona isoladamente, requer o envolvimento das pessoas para que os objetivos estratégicos sejam alcançados (HAMMUDA; DULAIMI, 1997). É nesta perspectiva que a liderança carismática se enquadra, pois, o líder impulsiona os liderados para alcançarem objetivos de forma entusiasta, com valores e crenças que resultem em significados de auto realização e motivação (CONGER, 2011).

Ugboro e Obeng (2000) afirmam em sua pesquisa que empresas bem-sucedidas em seus programas de qualidade, demonstram que a satisfação do colaborador é influenciada por melhorias no ambiente de trabalho, investimentos na saúde e segurança dos indivíduos e, a disponibilidade de programas de formação/capacitação. Destacam ainda que a satisfação destes indivíduos também é gerada por definição de metas, planejamento dos processos e, oportunidades de promoções internas e desenvolvimento de carreira. Neste sentido, é possível perceber a influência dos fatores extrínsecos ao indivíduo como contribuição à satisfação do colaborador diante da organização. Porém, isto demonstra que fatores intrínsecos, como as necessidades de reconhecimento interno e investimentos na capacitação são indispensáveis.

Estudos realizados em empresas de construção civil afirmam que, quanto maior o nível de comprometimento dos gerentes, maior o empoderamento dos liderados no trabalho. Os estudos apontaram que os cargos de gerência possuem maior facilidade de acesso à informação (relatórios, apresentações e contas anuais, acesso aos gestores, entre outros), o que facilita o desenvolvimento e crescimento profissional desta instância na organização. Demonstra-se, que as organizações, precisam encontrar meios de desenvolver mais pessoas capazes de gerir a si mesmas e, um menor número de gerentes, de forma que torne a cadeia hierárquica da organização mais eficaz. (HAMMUDA; DULAIMI, 1997). 
Professores de ensino fundamental relatam que os aborrecimentos no dia a dia de trabalho e a falta de condições para o trabalho são fatores que geram insatisfação. Já a eficácia de seu trabalho e a crença de um resultado positivo na aprendizagem dos seus alunos, é uma variável que influencia positivamente. Muitos professores citam o trabalho como uma missão, logo, o envolvimento com os alunos influencia em seu crescimento psicológico e, consequentemente, os motivam (QUAGLIA; MARION; MCINTIRE, 1991).

Em suma, pela capacitação é possível fornecer os mecanismos necessários para que os líderes invistam em suas equipes, individual ou coletivamente. A melhoria dos processos torna o caminho mais seguro para atingir metas e um melhor desenvolvimento das equipes, garantindo assim, maior eficiência organizacional (RANDENIYA; BAGGALEY; RAHIM, 1995).

\subsubsection{A liderança carismática: sensibilidade aos membros da equipe de trabalho}

Líderes carismáticos defendem sua posição e demonstram maior preocupação com os interesses dos seus liderados do que com ele mesmo. Estão atentos às necessidades de seus seguidores e, não somente da organização que pertencem. Demonstram interesse nas oportunidades e procuram expressar sua dedicação de forma desinteressada e altruísta. Assumem junto aos seguidores compromissos com total dedicação e preocupação. Este posicionamento faz com que conquistem um maior compromisso e esforço por parte dos seguidores (CONGER, 2011).

Considera-se que, o líder carismático tem um impacto considerável sobre os efeitos psicológicos da capacitação de sua equipe. Assim, assume o papel de influenciar a equipe concentrando-se em estratégias que favoreçam a autogestão e a autonomia de decisões em grupo (GREASLEY et al, 2005). Equipes autogeridas têm conquistado espaço nas organizações. O impacto do empoderamento nessas equipes se ressalta por oferecer às mesmas o poder de decisão, responsabilidades e autoridade diante de decisões organizacionais que lhes são transferidas, como definição de objetivos de desempenho e padrões de qualidade, compras de suprimento e materiais necessários, entre outras atividades. A oferta de maior autonomia por meio deste estilo de gestão, tem resultado em trabalhadores mais satisfeitos e, consequentemente, na redução do absenteísmo e, produção de produtos e serviços com maior qualidade (YUKL, 2011).

O líder contribui significativamente no estado emocional de sua equipe ao provocar sentimentos de autoestima e autodeterminação que reforçam positivamente na performance profissional das pessoas. Isso significa que um ambiente e trabalho amistoso impactam na qualidade das relações interpessoais, no comprometimento das pessoas e nos níveis de compromisso com a organização (LIDEN; WAYNE; SPARROWE, 2000). A liderança atua no sentido de gerenciar o contexto através de uma visão comum a todos, ao enfatizar as estratégias e os valores organizacionais que estão em voga. O desafio dos líderes é encontrar um ponto de equilíbrio entre os valores individuais e os valores organizacionais com vistas a gerar um significado para o trabalho através de estratégias que valorizem os processos e as pessoas. Nesse sentido, a atuação do líder está em promover uma relação de mutualidade e consenso com os seus subordinados (BURDETT, 1991).

Em pesquisa com mais de 400 enfermeiros de hospitais terciários de Ontara, foi possível constatar que quando os líderes incentivavam a autonomia, a tomada de decisão e a confiança no trabalho dos enfermeiros se tornavam mais latente, estes sentiam mais habilitados, pois vivenciavam emoções positivas diante do cargo. Nesse sentido, a tomada do poder acontece quando além do domínio intrínseco do poder, a organização oferece espaço para o empoderamento (LASCHINGER; FINEGAN; SHAMIAN, 2001).

Outro estudo com 337 funcionários e superiores imediatos de 60 grupos de trabalho identificou a influência das relações de trabalho com o comprometimento e a performance dos trabalhadores. Foi possível identificar que a relação de apoio e orientação do superior imediato e colegas de trabalho influenciam diretamente nos resultados individuais. Fato este, que se refere à crença de que o papel do líder impacta na motivação, na satisfação e no desempenho do liderado. Cabe ao líder o papel principal de fornecer o suporte imediato aos seus subordinados, para que estes se sintam acolhidos, seguros e possam desenvolver suas atribuições com qualidade e comprometimento (LIDEN; WAYNE; SPARROWE, 2000).

\subsubsection{A liderança carismática: capacidade de assumir risco pessoal}

Os líderes carismáticos demonstram por meio de seus comportamentos e atitudes, riscos pessoais, que muitas vezes são percebidos pelos seguidores como uma espécie de 'sacrifício'. Consequentemente, os líderes recebem a admiração e confiança dos seguidores, pois se estão dispostos a estes 'sacrifícios' e assumem tais riscos pessoais para 
concretizar o seu trabalho, é porque realmente acreditam no potencial dos resultados e da visão da organização. Essa percepção faz com que os seguidores sejam mais comprometidos e estejam alinhados nos mesmos processos (CONGER et al, 1997).

A construção de uma relação de confiança é baseada no respeito e confiança mútua e, o líder carismático constrói esta confiança por meio do exemplo pessoal. Estes líderes defendem sua posição demonstrando maior preocupação com os interesses dos seus seguidores do que com os seus próprios. Nesse caso, o risco pessoal pode incluir desde a possível perda de finanças pessoais, a possibilidade de ser demitido ou rebaixado, a perda de status, poder, autoridade e credibilidade. Quanto maior for o risco pessoal, maior é a confiança dos seguidores no líder. Quanto mais os líderes demonstrarem abertura para novos e elevados riscos pessoais ou, incidirem em altos custos pessoais, mais eles conquistam a afeição, no sentido de ser digno da confiança completa dos seus (CONGER, 2011).

\subsubsection{A liderança carismática: comportamento não convencional}

Os líderes carismáticos geralmente fazem uso de meios não convencionais para alinhar o compromisso da missão com seus seguidores e capacitá-los. Utilizam meios expressivos de ação, tanto verbal quanto não verbal, manifestam suas convicções, autoconfiança e dedicação para realizar o que eles programaram. Baseados em suas atitudes diferenciadas, com alta energia e persistência, desenvolvem uma alta motivação e entusiasmo (CONGER, 2011).

A motivação é um fenômeno variável e, se apresenta em quantidades diferentes que dependem da orientação da motivação. Desta forma, a motivação pode ser compreendida por dois fatores: i) motivação intrínseca (composta por fatores que envolvem a realização pessoal, possui vínculo com seus valores pessoais) ii) motivação extrínseca (está relacionada com fatores de recompensas externas, metas organizacionais, entre outros aspectos) (RYAN; DECY, 2000). Nesta linha de pensamento Conger e Kanungo (1988) expõe que o empoderamento não se trata apenas de delegação de maiores responsabilidades, para que o empoderamento ocorra de uma forma eficaz, é necessário despertar a motivação intrínseca do indivíduo.

A liderança carismática possui o comportamento não convencional como um diferencial devido às diversas escolhas na realização de suas tarefas, à capacidade de formular e articular uma visão inspiradora por comportamentos e ações que, demonstram que o líder e a sua a missão são extraordinários. Esse tipo de comportamento gera a percepção do carisma no seu seguidor (CONGER et al, 1997).

\subsubsection{A liderança carismática: sensibilidade com o ambiente de trabalho}

A liderança carismática apresenta uma maior percepção das necessidades dos seus seguidores e, se sensibiliza com oportunidades e possíveis conflitos ambientais que estes possam vir a ter. São líderes que atuam diretamente em processos de melhorias no ambiente de trabalho, de forma que promova maior qualidade de vida nas organizações e melhores relacionamentos (CONGER et al, 1997).

O ambiente social e de trabalho impacta diretamente na formação e desenvolvimento da personalidade dos indivíduos. Destes, o trabalho tem apresentado um alto nível de significação nas mudanças de humor e comportamentais dos trabalhadores, tendo em vista que, grande parte do tempo, as pessoas estão dentro do ambiente de trabalho. $O$ impacto das estruturas sociais organizacionais sobre o comportamento do empregado é muito maior que o impacto das suas características de personalidade e, as mudanças de comportamento podem ser percebidas através da cultura organizacional ou, do clima presente na organização ou, no ambiente onde o indivíduo trabalha. Comportamento é algo mutável e, por estar em um ambiente hostil, por vezes o indivíduo pode apresentar reações contrárias ao que dele se espera. Avaliar este tipo de evento interno é fundamental para contribuir com a satisfação do indivíduo e, consequentemente, com os resultados positivos por ele gerados (LASCHINGER; FINEGAN; SHAMIAN, 2001).

A motivação intrínseca deriva diretamente das experiências de um conjunto de tarefas realizadas pelo indivíduo. O modelo cognitivo busca identificar os fatores cognitivos pertencentes à tarefa em si, que produzem motivação e satisfação no trabalho. $O$ termo tarefa está relacionado com o conjunto de atividades que direcionam para um propósito, sendo avaliado somente a tarefa por si só e, não o contexto onde ela se insere. A capacitação, percebida como uma motivação intrínseca à tarefa consiste em quatro dimensões: significação, impacto, competência e escolha. A significação aborda o valor de uma tarefa com relação aos valores individuais, ou seja, o significado existente na tarefa. Já o impacto está relacionado com a contribuição do comportamento do indivíduo diante da tarefa. A dimensão competência se refere à autoeficácia ou a crença da capacidade plena de sucesso. $E$, a escolha se refere à responsabilidade do indivíduo em suas próprias ações (THOMAS; VELTHOUSE, 1990). 
A baixa autoeficácia influencia na evitação e rejeição de situações que exijam habilidades mais relevantes, por vezes, influenciados pelo medo ou por não acreditar em sua própria capacidade de resolução ou de desempenho. Este comportamento pode impedir a construção de novas habilidades e competências e, consequentemente de novas oportunidades na empresa ou mesmo, fora dela. Quando a autoeficácia é reconhecida intimamente pelo indivíduo, passa a desenvolver maior expectativa em atividades semelhantes àquelas que apresentaram maior desempenho (BANDURA, 1977).

Um estudo com professores de escolas públicas demonstrou que a autoeficácia e o crescimento profissional precedem a satisfação e o comprometimento no trabalho. Após identificar tais contribuições do ambiente de trabalho para o seu crescimento e desenvolvimento profissional, tendo satisfeitas suas necessidades pessoais, é possível identificar um aumento na satisfação e no comprometimento do trabalho dos indivíduos. O ambiente precisa contribuir com um meio que nutre, suporta e estimula o crescimento e desenvolvimento profissional, encorajando as percepções de competência, valor, propriedade e satisfação com a organização de trabalho (WU; SHORT, 1996).

Portanto, a satisfação do indivíduo pode ser mensurada pelo seu nível de engajamento em suas atividades. $\mathrm{O}$ engajamento do indivíduo no trabalho depende do quanto os valores pessoais estão alinhados aos valores organizacionais, ao quanto que suas atividades têm significado para si próprio. O poder de decidir por trabalhar com entusiasmo ou não, a ter interesse na empresa ou não, a apresentar qualidade ou não no trabalho, vai caracterizar se a relação entre as metas individuais e organizacionais estão em conflito ou não (BURDETT, 1991).

\section{PROCEDIMENTOS METODOLÓGICOS}

Este estudo objetiva identificar o nível de liderança carismática em profissionais que ocupam cargos de gestão em organizações de saúde do sul de Santa Catarina. Caracteriza-se como uma pesquisa descritiva e de campo, com técnica de análise dos dados predominantemente quantitativa.

Esse estudo foi realizado em duas organizações de saúde (hospital (1) e clínica de saúde (2)) localizadas na região sul de Santa Catarina (Brasil). No hospital há 262 trabalhadores, porém somente 220 aceitaram participar da pesquisa, o que corresponde a $84 \%$ dos respondentes. Na clínica de saúde há 43 trabalhadores, porém somente 38 aceitaram participar da pesquisa, o que corresponde a $88 \%$ dos respondentes. 0 critério de escolha destas instituições para a realização da pesquisa se deu pelo fato de ambas serem administradas por um mesmo gestor. No hospital o gestor é membro de uma sociedade, porém na clínica é sócio-proprietário. Considerando que ambas instituições são administradas pelo mesmo gestor, porém sendo de propriedades jurídicas distintas, percebeu-se a oportunidade de identificar o nível de liderança carismática neste campo de estudo.

A Tabela 1 apresenta o perfil dos respondentes da pesquisa. É possível perceber que nem todos os colaboradores responderam adequadamente o perfil.

Tabela 1 - Perfil dos respondentes da pesquisa.

\begin{tabular}{lccccccccccc}
\hline Itens & Gênero & $\mathbf{N}$ & Mínimo & Máximo & Média & $\begin{array}{c}\text { Desvio } \\
\text { padrão }\end{array}$ & $\mathbf{N}$ & Mínimo & Máximo & $\begin{array}{c}\text { Média } \\
\text { Desvio } \\
\text { padrão }\end{array}$ \\
\hline Tempo na & $\mathrm{M}^{*}$ & 36 & 1 & 43 & 6,92 & 11,929 & 4 & 1 & 8 & 5,25 & 2,986 \\
empresa & $\mathrm{F}^{*}$ & 197 & 1 & 37 & 4,44 & 5,616 & 20 & 1 & 11 & 4,50 & 3,204 \\
Idade & $\mathrm{M}^{*}$ & 35 & 20 & 65 & 33,57 & 13,561 & 4 & 22 & 49 & 36,00 & 11,106 \\
& $\mathrm{~F}^{*}$ & 194 & 18 & 65 & 32,36 & 7,900 & 18 & 18 & 41 & 29,89 & 7,451 \\
\hline
\end{tabular}

Fonte: Dados obtidos na pesquisa (2016).

* $M$ (masculino) /F (feminino)

É possível perceber, em ambas instituições, a predominância do gênero feminino. Por se tratarem de instituições de saúde, justifica a presença feminina em maior número. Em relação ao tempo de empresa, no hospital os homens estão, em média, há 6,92 anos na instituição, sendo que as mulheres estão há 4,4 anos. Na clínica os homens estão há 5,25 anos e as mulheres 4,50 anos.

No que se refere ao processo de coleta dos dados consistiu na aplicação de um instrumento de pesquisa baseado em Conger et al (1997), estruturado com 20 questões afirmativas, com uma escala de likert de 7 pontos e 1 (uma) questão aberta que buscou compreender, na visão dos respondentes, os desafios da liderança tanto do ponto de vista do líder, quanto do liderado.

De acordo com a literatura de Conger et al (1997), o instrumento de pesquisa foi estruturado considerando 5(cinco) dimensões de análise, quais sejam: i) visão estratégica e articulação (SVA) (composta por 7 afirmações); ii) 
sensibilidade ao ambiente (SE) (composta por 4 afirmações); iii) sensibilidade aos membros (SMN) (composta por 3 afirmações); iv) risco pessoal (PR) (composta por 3 afirmações); v) comportamento não convencional (VB) (composta por 3 afirmações).

A técnica de análise dos dados foi a estatística não-paramétrica, por se tratar de variáveis categóricas. A Inferência Estatística é composta por dois grandes grupos de técnicas: As Inferências Estatísticas Paramétricas e as Inferências Estatísticas Não Paramétricas.

Segundo Callegari-Jacques (2003), nos testes de inferências estatísticas paramétricas os valores da variável estudada devem ter distribuição normal ou aproximação normal, característica comum das variáveis quantitativas. Já os testes não paramétricos não possuem exigências quanto ao conhecimento da distribuição da variável na população, comum em variáveis qualitativas ou em estudos com tamanho de amostra pequeno.

Os testes estatísticos realizados foram de Shapiro-Wilk e o U de Mann-Whitney, considerando um nível de significância $(\alpha)$ de $5 \%$. Para a análise da questão qualitativa foram descritas as contribuições dos participantes quanto as similaridades de respostas e identificadas as frequências afirmativas.

O teste Shapiro-Wilk serviu para testar a normalidade dos dados da amostra e foi o escolhido por apresentar melhores resultados segundo estudo realizado por Torman, Coster e Riboldi (2012) e corroborado por Zar (1999).

A formulação de hipóteses para o teste Shapiro-Wilk é descrita na fórmula 1 a seguir:

$\left\{H_{0}:\right.$ a amostra provém de uma distribuição normal

$\left\{H_{1}:\right.$ a amostra não provém de uma distribuição normal

O teste de normalidade foi realizado mesmo considerando as variáveis categóricas, para confirmar que os testes não paramétricos são os mais adequados para o estudo. Neste sentido, foi possível constatar que os dados não provêm de uma distribuição normal, onde todos os p-valores dos testes de Shapiro-Wilk foram menores que 0,001.

De acordo com Siegel (1975), o teste $U$ de Mann-Whitney é utilizado quando são comparados os valores de dois grupos de amostras independentes e o nível de mensuração da variável é ordinal, característica das variáveis da escala de Likert.

Pode-se dizer que o teste $U$ de Mann-Whitney é o teste alternativo ao teste paramétrico $t$ de Student para duas amostras independentes (SHESKIN, 2004).

O teste de hipótese para o teste $U$ de Mann-Whitney é descrito conforme fórmula 2 a seguir,

$$
\left\{\begin{array}{l}
H_{0}: \mu_{1}=\mu_{2} \\
H_{1}: \mu_{1} \neq \mu_{2}
\end{array}\right.
$$

Onde, $\mu_{1}$ representa o escore médio dos Líderes em cada uma das afirmações avaliadas e $\mu_{2}$ representa o escore médio dos Liderados em cada uma das afirmações avaliadas na pesquisa. A discussão subsequente considera o teste de hipótese em cada dimensão que se segue.

\section{RESULTADOS}

Neste capítulo, serão apresentadas as 5 (cinco) dimensões da liderança carismática proposta por Conger et al (1997), i) visão estratégica e articulação (SVA); ii) sensibilidade ao ambiente (SE); iii) sensibilidade aos membros (SMN); iv) risco pessoal (PR); v) comportamento não convencional (VB), bem como os desafios da liderança em organizações de saúde na visão dos líderes e liderados.

\subsection{Dimensões da liderança carismática}

As dimensões da liderança carismática estão analisadas nas seções seguintes: visão estratégica e articulação; sensibilidade ao ambiente; sensibilidade aos membros; risco pessoal e comportamento não convencional.

\subsubsection{Visão estratégica e articulação (SVA)}

As organizações necessitam de pessoas visionárias, que vislumbrem ideias inovadoras, para que de forma mútua ambos atinjam seus ideais. O objetivo desta dimensão é buscar identificar se o indivíduo que ocupa o cargo de liderança possui facilidade em sistematizar a equipe frente à visão da organização (CONGER et al, 1997). A Tabela 2 apresenta o nível de liderança carismática na visão dos líderes e liderados em relação a dimensão de visão estratégica e articulação. 
Tabela 2 - Média do nível de liderança carismática em relação a dimensão visão estratégica e articulação (SVA)

\begin{tabular}{|c|c|c|c|c|c|c|c|}
\hline \multirow[b]{2}{*}{ Afirmações } & \multirow[b]{2}{*}{ Respondente } & \multicolumn{3}{|c|}{ Hospital } & \multicolumn{3}{|c|}{ Clínica de Saúde } \\
\hline & & $\mathbf{N}$ & Média & $\begin{array}{l}\text { Ude mann- } \\
\text { whitney }\end{array}$ & $\mathbf{N}$ & Média & $\begin{array}{c}\text { Ude } \\
\text { mann- } \\
\text { whitney }\end{array}$ \\
\hline Apresenta os objetivos desta organização & Líder & 30 & 5,7333 & 0960 & 4 & 5,2500 & 0757 \\
\hline de forma inspiradora. & Liderado & 220 & 5,5727 & 0,900 & 38 & 5,1053 & וכו, \\
\hline É inspirado e capaz de motivar as pessoas, & Líder & 30 & 5,6000 & & 4 & 5,2500 & \\
\hline $\begin{array}{l}\text { envolvendo de forma eficaz a importância } \\
\text { sobre o que os membros desta empresa } \\
\text { estão realizando. }\end{array}$ & Liderado & 219 & 5,4886 & 0,770 & 38 & 5,1053 & 1,000 \\
\hline Gera novas ideias consistentes para o & Líder & 30 & 5,6333 & 0.725 & 4 & 5,5000 & 0.983 \\
\hline futuro desta empresa. & Liderado & 218 & 5,5459 & 0,120 & 37 & 5,1351 & 0,983 \\
\hline Fala bem em público de forma & Líder & 30 & 4,9667 & $0.013^{*}$ & 4 & 5,7500 & 0.845 \\
\hline emocionante. & Liderado & 218 & 5,5367 & $0,013^{\wedge}$ & 36 & 5,4167 & 0,845 \\
\hline Tem visão, muitas vezes, para trazer à tona & Líder & 30 & 5,7333 & & 4 & 6,0000 & \\
\hline $\begin{array}{l}\text { muitas ideias e possibilidades para o } \\
\text { futuro desta empresa. }\end{array}$ & Liderado & 220 & 5,5773 & 0,829 & 37 & 5,2703 & 0,567 \\
\hline Aproveita muitas oportunidades, a fim de & Líder & 30 & 5,9667 & 0,363 & 4 & 5,5000 & 0.983 \\
\hline atingir as metas desta empresa. & Liderado & 219 & 5,5936 & 0,363 & 38 & 5,2895 & 0,983 \\
\hline $\begin{array}{l}\text { Prontamente reconhece sobre novas } \\
\text { oportunidades ambientais (condições }\end{array}$ & Líder & 30 & 5,8667 & & 4 & 5,2500 & \\
\hline $\begin{array}{l}\text { físicas e sociais favoráveis) que podem } \\
\text { facilitar a realização dos objetivos desta } \\
\text { empresa. }\end{array}$ & Liderado & 220 & 5,4636 & 0,425 & 38 & 5,2105 & 1,000 \\
\hline Escore_SVA_Médio & $\begin{array}{l}\text { Líder } \\
\text { Liderado }\end{array}$ & $\begin{array}{c}30 \\
214\end{array}$ & $\begin{array}{l}5,6429 \\
5,5708\end{array}$ & 0,449 & $\begin{array}{c}4 \\
38\end{array}$ & $\begin{array}{l}5,5000 \\
5,2899\end{array}$ & 0,873 \\
\hline
\end{tabular}

Fonte: Dados obtidos na pesquisa (2016).

${ }^{*} p$-valor $<0,05$.

Os dados retratam que não há diferença significativa no escore médio da dimensão visão estratégica e articulação (SVA) e na maioria das afirmações que compõem esta dimensão. A exceção foi constada na afirmação referente a capacidade do líder em falar bem em público de forma emocionante na opinião dos trabalhadores do Hospital. Nesta afirmativa, houve diferença significativa na opinião dos líderes e liderados. O líder percebe que possui em média influência menor ( $\bar{X}=4,9667)$ em relação a opinião dos liderados $(\bar{X}=5,5367)$. Ao observar as médias de ambas as instituições é possível perceber que os líderes apresentaram tendência de liderança carismática com médias superiores a 5 de uma escala de 1 a 7 pontos.

\subsubsection{Sensibilidade ao ambiente (SE)}

O objetivo desta dimensão é verificar se os líderes possuem habilidades para promover em seu ambiente de trabalho a sensibilidade da equipe para alcançar os resultados propostos, frente às limitações emergentes. Os gestores contemporâneos necessitam ter ao seu lado lideranças capazes de identificar possibilidades e oportunidades de melhorias em seu ambiente de trabalho com o objetivo de promover a qualidade de vida minimizando o impacto de fatores ambientais ou humanos que possam influenciar negativamente nos resultados e metas almejados (CONGER, 2011). Na Tabela 3 é apresentado o nível de liderança carismática em relação à dimensão sensibilidade ao ambiente (SE). 
Tabela 3 - Média do nível de liderança carismática em relação a dimensão sensibilidade ao ambiente (SE).

\begin{tabular}{|c|c|c|c|c|c|c|c|}
\hline \multirow[b]{2}{*}{ Afirmações } & \multirow[b]{2}{*}{ Respondente } & \multicolumn{3}{|c|}{ Hospital } & \multicolumn{3}{|c|}{ Clínica de Saúde } \\
\hline & & $\mathbf{N}$ & Média & $\begin{array}{c}\text { Ude } \\
\text { mann- } \\
\text { whitney }\end{array}$ & $\mathbf{N}$ & Média & $\begin{array}{l}\text { Ude } \\
\text { mann- } \\
\text { whitney }\end{array}$ \\
\hline \multirow{2}{*}{$\begin{array}{l}\text { Prontamente reconhece as restrições do ambiente } \\
\text { físico (limitações tecnológicas, falta de recursos, etc.) } \\
\text { que podem prejudicar o alcance dos objetivos desta } \\
\text { empresa. }\end{array}$} & Líder & 30 & 6,0667 & \multirow[b]{2}{*}{0,736} & 4 & 6,2500 & \multirow[b]{2}{*}{0,249} \\
\hline & Liderado & 220 & 5,7364 & & 38 & 5,3421 & \\
\hline \multirow{2}{*}{$\begin{array}{l}\text { Prontamente reconhece restrições no ambiente social } \\
\text { e cultural da organização (normas culturais, falta de } \\
\text { apoio das pessoas, etc.) que podem impedir o alcance } \\
\text { dos objetivos desta empresa. }\end{array}$} & Líder & 30 & 5,7667 & \multirow[b]{2}{*}{0,900} & \multirow{2}{*}{$\begin{array}{c}4 \\
38\end{array}$} & \multirow{2}{*}{$\begin{array}{l}5,7500 \\
5,3158\end{array}$} & \multirow[b]{2}{*}{0,664} \\
\hline & Liderado & 220 & 5,5227 & & & & \\
\hline \multirow{2}{*}{$\begin{array}{l}\text { Reconhece as habilidades e competências de outros } \\
\text { membros desta empresa. }\end{array}$} & Líder & 30 & 6,1333 & \multirow{2}{*}{0,235} & 4 & 6,5000 & \multirow{2}{*}{0,199} \\
\hline & Liderado & 219 & 5,6210 & & 38 & 5,2895 & \\
\hline \multirow{2}{*}{$\begin{array}{l}\text { Reconhece as limitações de outros membros desta } \\
\text { empresa. }\end{array}$} & Líder & 30 & 5,9667 & \multirow{2}{*}{0,387} & 4 & 6,0000 & \multirow{2}{*}{0,521} \\
\hline & Liderado & 218 & 5,5367 & & 38 & 5,2105 & \\
\hline \multirow{2}{*}{ Escore_SA } & Líder & 30 & 5,9833 & \multirow{2}{*}{0,485} & 4 & 6,1250 & \multirow{2}{*}{0,307} \\
\hline & Liderado & 218 & 5,6112 & & 38 & 5,2895 & \\
\hline
\end{tabular}

Fonte: Dados obtidos na pesquisa (2016).

${ }^{*} p$-valor $<0,05$.

Ao observar a Tabela 3, foi possível perceber que não houve diferenças significativas entre a percepção dos líderes e dos liderados em relação as mesmas afirmativas, bem como no escore da dimensão sensibilidade ao ambiente. As médias entre as instituições se apresentaram bem próximas, demonstrando que os líderes possuem uma alta propensão a terem sensibilidade ao ambiente em que atuam, pois, as médias entre líderes e liderados ficaram próximas de 6 pontos.

\subsubsection{Sensibilidade aos membros (SMN)}

Esta dimensão visa identificar se os líderes avaliados possuem as características de sensibilidade mediante os membros de sua equipe de trabalho. O capital humano é considerado um diferencial competitivo no mercado. As empresas têm investido estrategicamente em pessoas buscando satisfazê-las e motivá-las para que que permaneçam firmes no seu propósito e missão, sem relutar. Dispor de líderes que evidenciem práticas de humanização mediante a equipe de trabalho têm sido crucial. Líderes carismáticos se sensibilizam com os membros da equipe, com suas oportunidades e dificuldades, fazem mais por eles do que por si mesmos e, isso promove seguidores mais solidificados e leais que buscam junto ao líder, o alcance de metas e objetivos (CONGER, 2011). Na Tabela 4 é apresentado o nível de liderança carismática em relação a dimensão sensibilidade aos membros.

Tabela 4 - Média do nível de liderança carismática dos líderes e liderados em relação a dimensão sensibilidade aos membros (SMN)

\begin{tabular}{|c|c|c|c|c|c|c|c|}
\hline \multirow[b]{2}{*}{ Afirmações } & \multirow[b]{2}{*}{ Respondente } & \multicolumn{3}{|c|}{ Hospital } & \multicolumn{3}{|c|}{ Clínica de Saúde } \\
\hline & & $\mathbf{N}$ & Média & $\begin{array}{c}\text { Ude } \\
\text { mann- } \\
\text { whitney }\end{array}$ & $\mathbf{N}$ & Média & $\begin{array}{c}\text { Ude } \\
\text { mann- } \\
\text { whitney }\end{array}$ \\
\hline Influencia os demais através do desenvolvimento para & Líder & 30 & 6,1000 & \multirow{2}{*}{0,124} & 4 & 6,2500 & \multirow{2}{*}{0,170} \\
\hline gostar do que faz e respeito mútuo. & Liderado & 216 & 5,5509 & & 38 & 5,0526 & \\
\hline Mostra sensibilidade para as necessidades e & Líder & 30 & 6,0667 & \multirow{2}{*}{0,182} & 4 & 6,2500 & \multirow{2}{*}{0,287} \\
\hline sentimentos dos outros membros desta empresa. & Liderado & 215 & 5,4791 & & 38 & 5,1316 & \\
\hline \multirow{2}{*}{$\begin{array}{l}\text { Muitas vezes, manifesta preocupação pessoal com as } \\
\text { desta empresa. }\end{array}$} & Líder & 30 & 6,0333 & \multirow{2}{*}{0,529} & 4 & 6,2500 & \multirow{2}{*}{0,494} \\
\hline & Liderado & 216 & 5,5972 & & 38 & 5,3421 & \\
\hline \multirow{2}{*}{ Escore_SNM } & Líder & 30 & 6,0667 & \multirow{2}{*}{0,275} & 4 & 6,2500 & \multirow{2}{*}{0,184} \\
\hline & Liderado & 213 & 5,5524 & & 38 & 5,1754 & \\
\hline
\end{tabular}

Fonte: Dados obtidos na pesquisa (2016).

${ }^{*} p$-valor $<0,05$.

Os resultados da Tabela 4 também retrataram que não há diferenças significativas entre as médias dos líderes e liderados. No que tange ao nível de liderança carismática, ficou perceptível que as médias se aproximaram de 6 pontos, confirmando alta sensibilidade dos líderes para com os membros da equipe. 


\subsubsection{Risco pessoal (PR)}

O que se avalia nesta dimensão é se os indivíduos em cargos de liderança assumem riscos pessoais diante da posição de seu cargo e da equipe de trabalho. O resultado da equipe é reflexo do trabalho realizado pelo líder. Líderes carismáticos lideram pelo exemplo, assumindo riscos pessoais que são percebidos pelos seguidores como uma espécie de 'sacrifício', o que faz como que acreditem tanto no potencial da meta estabelecida pelo que o líder acredita. O resultado é a confiança, o comprometimento e a dedicação da equipe em prol dos objetivos propostos (CONGER et al, 1997). Na Tabela 5 é apresentado o nível de liderança carismática em relação a dimensão sensibilidade ao risco pessoal.

Tabela 5 - Média do nível de liderança carismática dos líderes e liderados em relação a dimensão risco pessoal (PR).

\begin{tabular}{|c|c|c|c|c|c|c|c|}
\hline \multirow[b]{2}{*}{ Afirmações } & \multirow[b]{2}{*}{ Respondente } & \multicolumn{3}{|c|}{ Hospital } & \multicolumn{3}{|c|}{ Clínica de Saúde } \\
\hline & & $\mathbf{N}$ & Média & $\begin{array}{c}\text { Ude } \\
\text { mann- } \\
\text { whitney }\end{array}$ & $\mathbf{N}$ & Média & $\begin{array}{c}\text { Ude } \\
\text { mann- } \\
\text { whitney }\end{array}$ \\
\hline \multirow{2}{*}{$\begin{array}{l}\text { Toma elevados riscos pessoais para o bem desta } \\
\text { empresa. }\end{array}$} & Líder & 30 & 4,2333 & \multirow{2}{*}{0,222} & 4 & 6,0000 & \multirow{2}{*}{0,521} \\
\hline & Liderado & 211 & 4,7488 & & 38 & 5,2105 & \\
\hline \multirow{2}{*}{$\begin{array}{l}\text { Muitas vezes paga do bolso muitas coisas para o bem } \\
\text { desta empresa. }\end{array}$} & Líder & 30 & 2,7333 & \multirow{2}{*}{0,131} & 4 & 4,5000 & \multirow{2}{*}{0,483} \\
\hline & Liderado & 202 & 3,3812 & & 37 & 3,8919 & \\
\hline \multirow{2}{*}{$\begin{array}{l}\text { Na realização dos objetivos desta empresa, se envolve } \\
\text { em atividades que envolvem um considerável risco } \\
\text { pessoal. }\end{array}$} & Líder & 30 & 3,7667 & \multirow[b]{2}{*}{0,209} & 4 & 6,0000 & \multirow[b]{2}{*}{0,121} \\
\hline & Liderado & 209 & 4,2632 & & 38 & 4,2895 & \\
\hline \multirow{2}{*}{ Escore_RP } & Líder & 30 & 3,5778 & \multirow{2}{*}{0,137} & 4 & 5,5000 & \multirow{2}{*}{0,255} \\
\hline & Liderado & 199 & 4,0905 & & 37 & 4,4414 & \\
\hline
\end{tabular}

Fonte: Dados obtidos na pesquisa (2016).

${ }^{*} p$-valor $<0,05$.

Os dados retratam que não há diferença significativa entre as médias dos líderes e liderados em ambas instituições. Nota-se que nesta dimensão as médias ficaram inferiores a 4 pontos em ambas as instituições na afirmativa quando destaca que o líder tende a não pagar do bolso muitas coisas para o bem da empresa. Nas demais variáveis percebe-se que o hospital apresentou médias inferiores as médias da clínica. Os dados retratam que os líderes da clínica tendem a assumir mais riscos do que os líderes do hospital.

\subsubsection{Comportamento não convencional (VB)}

Esta dimensão visa identificar se os líderes avaliados possuem comportamentos não convencionais mediante seus liderados para o alcance das metas. Liderar uma equipe têm se mostrado um desafio para muitos. As diferentes crenças, culturas, paradigmas, valores, constroem equipes não homogêneas e, que precisam de um gestor que saiba lidar com os mais diversos meios para alcançar o equilíbrio e a harmonia da equipe. Do contrário, estará fadado ao fracasso. O líder carismático busca meios não convencionais de fazer com que sua equipe de trabalho esteja engajada. Através de seus comportamentos, atitudes e habilidades diferenciadas, ele conquista a confiança dos seguidores e faz com que estejam alinhados em prol dos mesmos objetivos (CONGER et al, 1997). Na Tabela 6 é apresentado o nível de liderança carismática em relação a dimensão comportamento não convencional.

Tabela 6 - Média do nível de liderança carismática dos líderes e liderados em relação a dimensão comportamento não convencional (VB).

\begin{tabular}{|c|c|c|c|c|c|c|c|}
\hline \multirow[b]{2}{*}{ Afirmações } & \multirow[b]{2}{*}{ Respondente } & \multicolumn{3}{|c|}{ Hospital } & \multicolumn{3}{|c|}{ Clínica de Saúde } \\
\hline & & $\mathbf{N}$ & Média & $\begin{array}{c}\text { Ude } \\
\text { mann- } \\
\text { whitney }\end{array}$ & $\mathbf{N}$ & Média & $\begin{array}{c}\text { Ude } \\
\text { mann- } \\
\text { whitney }\end{array}$ \\
\hline \multirow{2}{*}{$\begin{array}{l}\text { Tem um comportamento não tradicional, a fim de } \\
\text { atingir as metas desta empresa. }\end{array}$} & Líder & 30 & 3,0333 & \multirow{2}{*}{0,095} & 4 & 4,2500 & \multirow{2}{*}{0,885} \\
\hline & Liderado & 208 & 3,7308 & & 38 & 4,3421 & \\
\hline \multirow{2}{*}{$\begin{array}{l}\text { Usa meios não tradicionais para alcançar objetivos } \\
\text { desta empresa. }\end{array}$} & Líder & 30 & 3,1333 & \multirow{2}{*}{0,323} & 4 & 4,0000 & \multirow{2}{*}{0,725} \\
\hline & Liderado & 208 & 3,5240 & & 38 & 3,6316 & \\
\hline \multirow{2}{*}{$\begin{array}{l}\text { Muitas vezes, apresenta um comportamento muito } \\
\text { original que surpreende outros membros desta } \\
\text { empresa. }\end{array}$} & Líder & 30 & 4,2333 & \multirow[b]{2}{*}{0,229} & 4 & 4,5000 & \multirow[b]{2}{*}{0,664} \\
\hline & Liderado & 211 & 4,6398 & & 38 & 4,7105 & \\
\hline \multirow{2}{*}{ Escore_CNC } & Líder & 30 & 3,4667 & \multirow{2}{*}{0,157} & 4 & 4,2500 & \multirow{2}{*}{0,918} \\
\hline & Liderado & 206 & 3,9482 & & 38 & 4,2281 & \\
\hline
\end{tabular}

Fonte: Dados obtidos na pesquisa (2016). ${ }^{*} p$-valor $<0,05$. 
Os dados retratam nesta dimensão que não há diferença significativa na opinião dos líderes e liderados quando avaliam o comportamento não convencional do líder. Neste sentido, é perceptível que os líderes do hospital apresentaram médias inferiores aos líderes da clínica. Esse resultado parece indicar que os líderes do hospital tendem a apresentar comportamentos mais tradicionais no alcance das metas, objetivos e atitudes que venham surpreender os liderados. As médias da clínica tiveram resultados semelhantes, porém 1 ponto superior ao hospital, dando a entender que estes líderes atuam dentro de certa normalidade, sem tampouco chamar a atenção do liderado quanto a um comportamento diferenciado.

\subsection{Os desafios da liderança na visão dos líderes e liderados}

Esta seção aborda os principais desafios percebidos pelos líderes e pelos liderados dentro de seus contextos de trabalho. O ambiente de trabalho é um fator que pode influenciar diretamente nos resultados do líder ou do liderado. As empresas aqui estudadas têm suas peculiaridades por se tratarem de ambientes que lidam diretamente com a dor e o sofrimento humano. O que faz com que os trabalhadores da área da saúde necessitem encontrar um ponto de equilíbrio entre suas emoções e seus objetivos profissionais (SILVA, 2009).

O trabalho no campo da saúde exige práticas solidificadas e condizentes com o objetivo final, os valores da empresa e o cuidado com o trabalhador. Isso se deve ao fato de que, resultados precisam ser gerados mesmo em meio a um contexto hostil e insalubre. Ambientes de saúde necessitam de atendimento diferenciado aos pacientes que, por se encontrarem em situações desconfortáveis de dor, estresse, sofrimento, medo ou quaisquer outras emoções envolvidas em seu processo patológico, precisam se sentir seguros e acolhidos por estes serviços (HENNINGTON, 2008).

A relação de trabalho existente possui uma ampla gama de relacionamentos que exigem atenção e cuidado redobrado para que os processos aconteçam da forma mais segura possível e, deve ser baseada na confiança mútua, no respeito e no trabalho em equipe. Pois, cada atividade dentro do ambiente requer saberes técnicos e práticos que complementam as demais e, pode comprometer todo o processo de diagnóstico ou cura. Devido à complexidade de todo o funcionamento do atendimento na saúde, atuar no treinamento e desenvolvimento das equipes é fundamental para o alcance do propósito (NUNES et al, 2006).

$\mathrm{Na}$ realização da pesquisa, os respondentes (líderes e liderados) puderam livremente descrever sobre os principais desafios que percebem na atuação das lideranças, em ambas as instituições avaliadas. Durante a avaliação das respostas, foi possível identificar 16 (dezesseis) fatores citados. Dentre estes, 03 deles apresentaram altas frequências tanto por líderes quanto pelos liderados: i) Engajamento, motivação e trabalho em equipe; ii) Gestão da equipe de trabalho; iii) Organização de tarefas e, realização e conhecimento dos processos. Outros dois fatores tiveram destaque em ambas as categorias (líderes e liderados) com menor frequência, mas não com menor relevância, são eles: i) Comportamento e cultura organizacional; ii) Alcance de metas e objetivos.

Nos relatos dos respondentes foi possível evidenciar que manter a equipe motivada, engajada e unida em prol do mesmo objetivo é considerado um dos maiores desafios para os líderes. Isto se deve provavelmente à diversidade existente entre as equipes, que podem ser: variação de idade, personalidades diferentes, problemas individuais dos membros, entre outros.

Tabela 7 - Fatores desafiadores no exercício da liderança na visão dos líderes e liderados.

\begin{tabular}{|c|c|c|c|c|c|c|}
\hline Fatores & $\begin{array}{l}\text { Liderados } \\
\text { Clínica }\end{array}$ & $\begin{array}{l}\text { Liderados } \\
\text { Hospital }\end{array}$ & $\begin{array}{c}\text { Frequência } \\
\text { Total } \\
\text { Liderados }\end{array}$ & $\begin{array}{c}\text { Líder } \\
\text { Hospital }\end{array}$ & $\begin{array}{l}\text { Líderes } \\
\text { Clínica }\end{array}$ & $\begin{array}{l}\text { Frequência } \\
\text { Total Líderes }\end{array}$ \\
\hline $\begin{array}{l}\text { Engajamento, motivação e trabalho em } \\
\text { equipe }\end{array}$ & 6 & 42 & 48 & 11 & 1 & 12 \\
\hline Gestão da equipe de trabalho & 3 & 33 & 36 & 7 & & 7 \\
\hline $\begin{array}{l}\text { Organização de tarefas e, realização e } \\
\text { conhecimento dos processos }\end{array}$ & 3 & 33 & 36 & 7 & 1 & 8 \\
\hline $\begin{array}{l}\text { Recursos técnicos, humanos e } \\
\text { financeiros }\end{array}$ & 1 & 24 & 25 & & & 0 \\
\hline $\begin{array}{l}\text { Comportamento e cultura } \\
\text { organizacional }\end{array}$ & 1 & 19 & 20 & 8 & & 8 \\
\hline Alcance de metas e objetivos & 1 & 18 & 19 & 9 & & 9 \\
\hline Comunicação e feedback & 1 & 17 & 18 & & & 0 \\
\hline
\end{tabular}


Relacionamento interpessoal (médicos, funcionários e pacientes)

Inteligência emocional e empatia

Mediação de conflitos e resolução de problemas

Treinamento e Desenvolvimento

Modelo de Gestão

\begin{tabular}{|c|c|c|c|c|}
\hline 4 & 15 & 19 & 3 & 3 \\
\hline 1 & 15 & 16 & 1 & 1 \\
\hline 4 & 9 & 13 & 1 & 1 \\
\hline 1 & 7 & 8 & 6 & 6 \\
\hline \multirow[t]{2}{*}{1} & 4 & 5 & & 0 \\
\hline & 4 & 4 & & 0 \\
\hline 1 & 4 & 5 & & 0 \\
\hline \multirow[t]{2}{*}{2} & 2 & 4 & 1 & 1 \\
\hline & & 0 & 1 & 1 \\
\hline 30 & 246 & 276 & 55 & 2 \\
\hline
\end{tabular}

Conhecimento técnico

Ética

Reconhecimento e autonomia

Tomada de decisão

Total de Frequência

Fonte: Dados obtidos na pesquisa (2016).

Ryan e Decy (2000) destacam que a motivação para o trabalho pode ser percebida de duas maneiras: intrínseca ao indivíduo e extrínseca a ele, o que sugere que este indivíduo pode ser motivado por estímulos externos, que dependem de recursos providos pela instituição ou gerados pelo próprio líder. Neste pressuposto, o fator comportamento e cultura organizacional, também citado com muita relevância, pode ser considerado como um complemento para o desafio anterior, tendo em vista que na visão de líderes e liderados existe dificuldade para a inserção de uma nova cultura, principalmente em funcionários com muito tempo de casa ou de setor, acostumados em realizar as mesmas atividades há muito tempo ou, que mantiveram o mesmo líder por muito tempo. Laschinger, Finegan e Shamian (2001) afirmam que o comportamento é algo mutável e é moldado pelas organizações, ressalta inclusive que, o ambiente organizacional reflete diretamente na satisfação do indivíduo no trabalho e impacta em seu comportamento. Portanto, a necessidade de investir na mudança de cultura permanece, mesmo que, com suas resistências.

Gerenciar a equipe de trabalho foi outro fator pontuado também por ambos os respondentes como um desafio às lideranças. Diante das respostas, foi possível identificar que os líderes apresentam dificuldades para se posicionar enquanto gestor da equipe. Falta de autoridade e pulso firme foram elencados como fatores que dificultam a liderança. Falta de entonação e firmeza na voz também foram citados como complementos desta dificuldade. Cabe ao líder gerenciar a equipe de trabalho e buscar um ponto de equilíbrio entre os valores individuais dos membros da equipe de trabalho e os valores organizacionais, é necessário realizar os ajustes necessários para que ambas as partes satisfaçam suas necessidades (BURDETT, 1991).

O cumprimento dos processos é crucial para o bom resultado das atividades e o alcance das metas, por isso, o conhecimento dos mesmos e a boa divisão e organização de tarefas é fundamental para que a realização destes seja feita. Falta de organização e de divisão de tarefas foram elencados como causas de processos limitados e resultados não alcançados, inclusive, causa de desmotivação na equipe por sobrecarga de alguns em detrimento de outros. Falta de conhecimento do processo que é de responsabilidade do líder foi citado como um desafio acompanhado de pouco tempo na função. Conger (2011) ressalta que os líderes carismáticos praticam comportamentos não convencionais e, estes comportamentos atraem seguidores e os motivam na mesma causa do líder, sendo necessário, portanto, que o líder encontre meios de fazer com que a equipe queira seguir os seus passos, que sintam confiança no seu trabalho e no potencial das metas e planos traçados.

O fato de serem duas instituições privadas remete uma maior necessidade do cumprimento de rotinas para o alcance de metas e objetivos. Este foi um fator citado também com forte frequência por ambos e, considerado desafiador. Entre as metas é possível considerar aquelas de teor quantitativo (faturamento, maior custo benefício, menor despesa, cuidado e manutenção de equipamentos, fluxo de compras e estoques etc.) e de teor qualitativo (alcance da satisfação dos clientes, atendimento de excelência, qualidade nos serviços ofertados etc.). A contribuição do líder nos resultados da equipe é um reflexo do trabalho por ele praticado, sua influência impacta significativamente no empoderamento e engajamento da equipe com a organização de trabalho (LIDEN; WAYNE; SPARROWE, 2000).

Os liderados citaram também com considerável relevância, o que não ocorreu com os líderes, os seguintes fatores: i) Recursos técnicos, humanos e financeiros; ii) Comunicação e feedback; iii) Relacionamento interpessoal. No primeiro item destacaram a falta de investimento financeiro em novos instrumentos de trabalho (aparelhos, tecnologias, etc.), bem como a falta de condições financeiras para reformas e novas contratações para aumento do quadro profissional. No item comunicação e feedback ressaltaram a necessidade de os líderes ouvirem mais os liderados frente às situações que os envolvem, bem como, frente às suas necessidades particulares. Solicitaram ainda a devolução de feedbacks relacionados a problemas que envolvem a equipe ou o liderado individualmente. Com relação ao item 
relacionamento interpessoal, os liderados concluíram que é desafiador aos líderes o fato de terem que manter um relacionamento interpessoal adequado com diversas áreas diferenciadas, como os médicos, familiares, demais setores do hospital ou clínica e direção. Conger et al (1997) citam que líderes carismáticos se sensibilizam com os membros da equipe de trabalho, evidenciando a necessidade de manter um vínculo estreito com os membros da equipe, para que, estes possam discutir abertamente suas necessidades e anseios. Ainda, estimular a compreensão da situação atual das instituições em que trabalham para que absorvam com maior leveza as restrições impostas e atuem com maior grandiosidade naquilo que lhes é cabível.

\section{CONCLUSÃO}

O objeto deste trabalho foi identificar o nível de liderança carismática em profissionais que ocupam cargos de gestão em organizações de saúde do sul de Santa Catarina. Para tanto, foi utilizado o instrumento de Conger et al (1997) estruturado com 20 questões afirmativas, com uma escala de likert de 7 pontos e 1 (uma) questão aberta que buscou compreender, na visão dos respondentes, os desafios da liderança tanto do ponto de vista do líder, quanto do liderado.

Diante dos resultados obtidos foi possível evidenciar que os líderes do hospital e da clínica tem uma prédisposição à liderança carismática, tendo em vista que foram avaliados nos diversos critérios da dimensão visão estratégica e articulação com médias superiores à cinco. Considerando que, as instituições investigadas fazem parte de um mesmo grupo de empresas (com sócio proprietário comum a ambas), é possível afirmar que o modelo de gestão influencia positivamente nesse aspecto. Nessas instituições os líderes participam de reuniões semanais, quinzenais ou mensais com a direção ou os gestores principais e, recebem deles autonomia para desenvolver seu trabalho com as equipes. Outro ponto importante está na transparência das instituições com os funcionários, principalmente com os líderes. Esses participam ativamente dos processos de tomadas de decisão e construções estratégicas dos projetos em que estão incluídos ou tem algum tipo de relação.

Outro ponto digno de nota foi a evidência significativa entre a percepção de líderes e liderados no que diz respeito ao ambiente de trabalho, tendo apresentado inclusive, médias muito próximas em ambas as instituições e, que demonstram propensão dos líderes à liderança carismática. Nessas instituições, os líderes têm papel ativo no sentido de contribuir no processo de melhorias do ambiente de trabalho e, inclusive são influenciados para isso.

Na dimensão sensibilidade com os membros da equipe, devido a forte influência da cultura presente em ambas as instituições e ao papel ativo dos gestores, existe uma relação de proximidade e confiança entre os líderes e liderados, em sua grande maioria. Os resultados indicam que parece existir nestes locais de trabalho, o estímulo à boa convivência, ao respeito, ao atendimento de excelência ao cliente interno (funcionários e médicos) e externo (pacientes, fornecedores e visitantes). Nesse sentido, os líderes têm papel fundamental para garantir que os seus liderados se sintam acolhidos no seu ambiente de trabalho.

Insta observar que os líderes da clínica têm mais propensão a assumir riscos que os líderes do hospital, porém a média de ambos permaneceu abaixo de 4 pontos. O mesmo ocorre com o comportamento não convencional, em que ambos os líderes não apresentaram médias superiores, demonstrando atuarem com comportamentos mais tradicionais no alcance de metas e objetivos, sem influenciar ou impressionar o liderado. Por se tratarem de instituições cujo foco de negócio é a saúde, existem muitos protocolos e processos que acabam engessando um pouco e não permitindo comportamentos e atitudes muito desviantes. O que talvez explique o fato de ambas as dimensões risco pessoal e comportamento não convencional terem sido avaliadas com média inferior ao ponto de corte para liderança carismática.

A questão qualitativa demonstrou que existe uma sinergia entre líderes e liderados e que estes convergem dos mesmos pensamentos no que condiz aos principais desafios. Percebeu-se que os liderados identificam a dificuldade dos líderes em manter e proporcionar uma equipe engajada, motivada e que trabalhe em harmonia. Os resultados da tabela 3 puderam evidenciar que os líderes destas instituições têm conseguido efetuar este trabalho, mesmo que não seja em sua totalidade.

Neste sentido, conclui-se que os líderes do hospital e da clínica de saúde têm um perfil semelhante, com propensão à liderança carismática, porém, com restrições e limitações que precisam ser avaliadas e desenvolvidas. Tendo em vista que, quando se fala em saúde, não há como arriscar demais, devendo se seguir modos mais seguros de trabalho, sem perder a humanização e o foco no negócio.

Portanto, as limitações deste estudo estão norteadas nas questões metodológicas. Devido a não normalidade dos dados, não foi possível utilizar outros métodos quantitativos que permitissem compreender melhor os fenômenos. Sendo assim, sugere-se para estudos futuros a utilização de outra escala para medir o nível de liderança carismática. 


\section{REFERÊNCIAS}

BANDURA, A. Analysis of self-efficacy theory of behavioral change. Cognitive Therapy and Research, v. 1, n. 4, p. 287$310,1977$.

BEDELL-AVERS, K. E.; HUNTER, S. T.; MUMFORD, M. D. Conditions of problem-solving and the performance of charismatic, ideological, and pragmatic leaders: A comparative experimental study. The Leadership Quarterly, n. 19, p. 89-106, 2008.

BURDETT, J. O. "What is Empowerment Anyway"? Journal of European Industrial Training, v. 15, p. 6-15, 1991.

CALLEGARI-JACQUES, S. M. Bioestatística: Princípios e Aplicações. Porto Alegre: Artmed, 2003.

CONGER, J. A. Charismatic Leadership. In: BRYMAN; A.; COLLINSON, D.; GRINT, K.; JACKSON, B.; UHL-BIEN, M. Leardership: SAGE Handbook of Leadership. London: Sage, 2011. p. 86-102.

CONGER, J. A.; KANUNGO, R. N. The Empowerment Process: Integrating Theory and Practice. Academy ol Management Feview, v. 13, n. 3, p. 471-482, 1988.

CONGER, J. A. et al. Measuring Charisma: Dimensionality and Validity of the Conger-Kanungo Scala of Charismatic Leadership. Revue canadienne des sciences de l'administration, v. 14, n. 3, p. 290-302, 1997.

DOW, T. E. The Theory of Charisma. Social Quarterly, v. 10, n. 3, p. 306-318, 1969.

FIOL, M. C.; HARRIS, D.; HOUSE, R. Charismatic leadership: Strategies for effecting social change. The Leadership Quarterly, v. 10, n. 3, p. 449-483, 1999.

GRIFFITH, J. et al. How outstanding leaders lead with affect: An examination of charismatic, ideological, and pragmatic leaders. The Leadership Quarterly, v. 26, n. 4, p. 502-517, 2015.

GOMES, A. R.; CRUZ, J. Abordagem carismática e transformacional: modelos conceptuais e contributos para o exercício da liderança. PSICOL. USP, v. 18, n. 3, p. 143-161, 2007.

GREASLEY, K. et al. Employee perceptions of empowerment. Employee Relations, v. 27, n. 4, p. 354-368, 2005.

HAMMUDA, I.; DULAIMI, M. F. The theory and application of empowerment in construction: a comparative study of the different approaches to emporwerment in construction, service and manufacturing. International Journal of Project Gestão, v. 15, n. 5, p. 289-296, 1997.

HENNINGTON, E. A. Gestão dos Processos de Trabalho e Humanização de Saúde: reflexões a partir da ergologia. Revista Saúde Pública, v. 42, n. 3, p. 555-61, 2008.

LASCHINGER, H. K. S.; FINEGAN, J.; SHAMIAN, J.Promoting Nurses' Health: Effect of Empowerment on Job Strain And Work Satisfaction. Nursing Economics, v. 19, n. 2, p. 42-52, 2001.

LIDEN, R. C.; WAYNE, S. J.; SPARROWE, R. T. An Examination of the Mediating Role of Psychological Empowerment on the Relations Between the Job, Interpersonal Relationships, and Work Outcomes. Journal of Applied Psychology, v. 85, n. 3, p. 407-416, 2000.

NUNES, I. M. et al. O trabalho em saúde no contexto hospitalar: processos e necessidades como subsídios para a formação profissional. Revista de Enfermagem, v. 10, n. 3, p. 509-513, 2006.

OLIVEIRA, F. P.; DELFINO, I. A. L. Produção Científica sobre o Processo de Liderança. Revista de Administração, Contabilidade e Sustentabilidade, v. 3, n. 4, p. 104-126, 2013.

QUAGLIA, R.; MARION, S.F.; MCINTIRE, W. G. The relationship of teacher satisfaction to perceptions of school organization, teacher empowerment, work conditions, and community status. Education, v. 112, n. 2, p. 206-2016, 1991.

RANDENIYA, R; BAGGALEY, N.; RAHIM, M. A. Total quality management: the need to uncouple empowerment. Journal Total Quality Management, v. 6, n. 3, p. 215-220, 1995. 
RYAN, R.M.; DECl, E.L. Intrinsic and Extrinsic Motivations: Classic Definitions and New Directions. Contemporary Educational Psychology, Rochester, NY, v. 25, n. 1, p. 54-67, 2000.

SHESKIN, D. J. Handbook of Parametric and Nonparametric Statistical Procedures. Boca Raton: Chapman \& Halucrc, 2004.

SIEGEL, S. Estatística Não-paramétrica Para as Ciências do Comportamento. São Paulo: McGraw-Hill, 1975.

SILVA, L. C. O sofrimento psicológico dos profissionais de saúde na atenção ao paciente de câncer. Psicologia para América Latina, n. 16, 2009.

SILVA, A. S.; CARVALHO NETO, A. Uma contribuição ao estudo da liderança sob a ótica weberiana de dominação carismática. Revista de Administração Mackenzie, v. 13, n. 6, p. 20-47, 2012.

THOMAS, K. W.; \& VELTHOUSE, B. A. Cognitive elements of empowerment: An "interpretive" model of intrinsic task motivation. Academy of Management Review, v. 15, n. 4, p. 666-681, 1990.

TORMAN, V. B. L.; COSTER, R.; RIBOLDI, J. Normalidade de variáveis: métodos de verificação e comparação de alguns testes não-paramétricos por simulação. Revista HCPA, v. 32, n. 2, p. 227-243, 2012.

UGBORO, I. O.; OBENG, I. Top management leadership, employee empowerment, job satisfaction, and customer satisfaction in TQM organizations: an empirical study. Journal Of Quality Management, v. 5, p. 247-272, 2000.

WILLNER, A.R. The Spellbinders: Charismatic Political Leadership. La Mesa, CA, U.S.A.: Gargoyle Books, IOBA, 1984. WU, V; SHORT, P. M. The relationship of empowerment to teacher job commitment and job satisfaction. Journal of Instructional Psychology, v. 23, n. 1, p. 85-89, 1996.

YUKL, G. Contingency Theories of Effective Leadership. In: BRYMAN; A.; COLLINSON, D.; GRINT, K.; JACKSON, B.; UHLBIEN, M. Leardership. SAGE Handbook of Leadership. London: Sage, 2011. p. 286-298.

ZAR, J. H. Biostatistical analysis. Upper Saddle River, N.J.: Prentice Hall, 1999. 